\title{
Xamanismos Guarani e Tradução no Encontro de Saberes*
}

\author{
Isabel Santana de Rose ${ }^{1}$ \\ Geraldo Karaí Okenda \\ ${ }^{1}$ Universidade Federal de Alagoas, Maceió, AL, Brasil \\ ${ }^{2}$ Pesquisador guarani independente, Florianópolis, SC, Brasil
}

\section{Resumo}

Neste trabalho, propomos abordar o material de um dos módulos da disciplina "Artes e ofícios dos saberes tradicionais: curas e cuidados", vinculada à Formação Transversal em Saberes Tradicionais da UFMG. Esse módulo foi ministrado por Alcindo Wherá Tupã e Geraldo Karaí Okenda, lideranças espirituais guarani de Santa Catarina. Com base no material das aulas, chamamos atenção para a criatividade presente em suas falas ao levantar aspectos centrais da cosmologia e do sistema xamânico guarani, procurando traduzi-los para os alunos não indígenas. Também propomos relacionar este material com nossas pesquisas anteriores sobre a participação dos moradores da aldeia Yynn Morothi Wherá (Biguaçu, SC) em uma rede xamânica contemporânea denominada Aliança das Medicinas. Trata-se de um movimento protagonizado especialmente pelos integrantes de uma família extensa indígena específica e que se encontra ligado a um projeto amplo de fortalecimento do xamanismo e de manutenção do nhandereko ou "modo de ser" guarani.

Palavras-chave: Encontro de Saberes. Xamanismo. Tradução. Medicina Tradicional.

\section{Guarani Shamanisms and Translation in the University}

\begin{abstract}
In this text we intend to approach the material from one of the modules of the course "Arts and crafts of traditional knowledge: care and healing", which is part of the Traditional Knowledge Program from the Federal University of Minas Gerais (Belo Horizonte, Brazil). This module was taught by Alcindo Wherá Tupã and Geraldo Karaí Okenda, Guarani spiritual leaders from Santa Catarina state. Based on the material from their classes, we highlight Alcindo and Geraldo's creativity in bringing up central aspects of the Guarani cosmological and shamanic system and attempting to translate them to the non-Indian students. We also propose to connect this material with our previous research about the participation of the inhabitants from the Guarani village Yynn Morothi Wherá in a contemporary shamanic network called Medicine Alliance. This movement involves especially members from a specific extended Indigenous family, and is connected to a broad project of shamanic revival and maintenance of the nhandereko, or Guarani "way of being".
\end{abstract}

Keywords: Guarani Knowledge. Shamanism. Translation. Traditional Medicine.

\footnotetext{
* Isabel de Rose realizou trabalho de campo na aldeia Yynn Morothi Wherá entre 2006 e 2008. Geraldo Karaí Okenda, que foi um interlocutor central da pesquisa já nesse período, participou como professor-assistente na disciplina “Artes e ofícios dos saberes tradicionais: curas e cuidados" na UFMG em 2015.
} 


\section{Introdução}

$\mathrm{N}$

este trabalho, propomos abordar o material de um dos módulos da disciplina de "Artes e ofícios dos saberes tradicionais: curas e cuidados", ${ }^{1}$ vinculada à Formação Transversal em Saberes Tradicionais da Universidade Federal de Minas Gerais (UFMG). Esse módulo foi realizado em maio de 2015 e ministrado por Alcindo Wherá Tupã e Geraldo Karaí Okenda, lideranças espirituais guarani do litoral Sul de Santa Catarina. Também propomos relacionar este material às nossas pesquisas de campo anteriores a respeito da participação dos moradores da aldeia Yynn Morothi Wherá (Biguaçu, SC) em uma rede xamânica contemporânea denominada Aliança das Medicinas. Trata-se de um movimento que vem sendo protagonizado especialmente pelos integrantes da família extensa de Alcindo Wherá Tupã e Rosa Poty Djá e que se encontra ligado a um projeto amplo de fortalecimento do xamanismo e de manutenção do nhandereko ou "modo de ser" guarani².

O texto encontra-se dividido em três partes. Nesta primeira parte apresentamos um histórico do Encontro de Saberes no Brasil e sua relação com a Formação Transversal em Saberes Tradicionais da UFMG. A seguir, trazemos alguns dados sobre os Guarani no Sul do Brasil e descrevemos a trajetória de Alcindo Wherá Tupã e Rosa Poty Djá, apontando para o papel desse casal e de sua família em um amplo processo de fortalecimento e de revitalização cultural que vem ocorrendo entre os Guarani no Sul do Brasil e que envolve reivindicações políticas e iniciativas em áreas como educação, saúde e xamanismo ver, entre outros, Rose (2010), Langdon e Rose (2012; 2014), Rose e Langdon (2013). Situamos dentro desse contexto mais amplo a participação dessa família extensa indígena na formação da Aliança das Medicinas, rede xamânica contemporânea estabelecida ao longo dos últimos 20 anos no Estado de Santa Catarina. Já na terceira parte do texto, enfocamos a análise do material das aulas de Alcindo e Geraldo na disciplina "Artes e ofícios dos saberes tradicionais: curas e cuidados". Buscamos estabelecer relações entre este material tanto com uma reflexão sobre o Encontro de Saberes e sua potencialidade quanto com nossas pesquisas anteriores sobre a participação dos moradores da aldeia

Esta disciplina foi ministrada por quatro mestres e mestras que vieram de diferentes regiões do Brasil, sendo cada um deles acompanhados por um assistente: Seu Badu, liderança quilombola da comunidade do Matição, Jaboticatubas, MG; Lucely Pio, especialista em plantas medicinais e moradora da comunidade quilombola de Cedros, Goiás; Dona Jaçanã, indígena pataxó, parteira e curandeira da Bahia; e Alcindo Wherá Tupã, liderança espiritual guarani de Santa Catarina. Os mestres e assistentes foram convidados por professores ligados à Formação Transversal em Saberes Tradicionais que tinham relações prévias com eles e suas comunidades.

2 As referências ao nhandereko são recorrentes nas análises recentes sobre os Guarani. Esse termo costuma ser traduzido como "sistema", "ethos", "estilo de vida", "modo de ser" ou “cultura" guarani (DARELLA, 2004; LADEIRA, 2007; MELLO, 2006; PISSOLATO, 2007; MACEDO, 2010; entre outros). 
Yynn Morothi Wherá na rede da Aliança das Medicinas. Destacamos, entre outros aspectos, a criatividade presente nas falas de seu Alcindo e Geraldo nas aulas na UFMG, ao levantar aspectos centrais da cosmologia e do sistema xamânico guarani e procurar traduzi-los para o público não indígena que participou da disciplina.

Coordenado pelo antropólogo José Jorge de Carvalho e desenvolvido na Universidade de Brasília (UnB) a partir de 2010, o Encontro de Saberes constitui um desdobramento da luta por uma política de inclusão e de ações afirmativas, principalmente para negras, negros e indígenas, nas universidades brasileiras. Esse programa encontra-se vinculado às atividades do Instituto Nacional de Ciência e Tecnologia (INCT) de Inclusão no Ensino Superior e na Pesquisa e pode ser considerado como um marco inaugural no que diz respeito às iniciativas direcionadas para a inclusão dos mestres e mestras dos saberes tradicionais nas universidades. Carvalho, o idealizador dessa proposta, tem sido um importante ativista na luta pelas políticas de ação afirmativa desde o final dos anos 1990, trazendo em muitos de seus trabalhos uma denúncia à desigualdade étnico-racial dramática que caracteriza as universidades brasileiras - ver, entre outros, Carvalho $(2010 ; 2011)$. Ele considera que a entrada dos negros e indígenas nas universidades deve passar necessariamente pela inclusão dos saberes negros e indígenas (CARVALHO, 2010). Nesse sentido, para além de políticas de ações afirmativas para estudantes indígenas e afro, é importante uma ampliação do universo dos saberes presentes nas universidades, possibilitando abranger uma "multiepistemia"; e "[...] uma ampliação radical do corpo docente universitário, englobando os mestres e sábios indígenas e afro como professores de cursos regulares em diferentes áreas" (CARVALHO, 2010, p. 241).

Pensadas em termos mais amplos, as experiências de encontros de saberes em contextos acadêmicos incluem pelo menos três tipos de iniciativa: aquelas em que os professores são os mestres e mestras dos conhecimentos tradicionais, como é o caso da iniciativa que enfocamos neste texto; aquelas nas quais os(as) estudantes tiveram acesso à universidade por meio de políticas de ação afirmativa ou vestibular diferenciado; e os cursos de natureza intercultural, que incluem as licenciaturas (ou bacharelados) indígenas e quilombolas, entre outros ${ }^{3}$. Essas experiências remetem diretamente a debates anteriores ligados à crescente afirmação e reconhecimento das diferenças étnicas, de gênero, orientação sexual, religiosa, entre outras, tanto na América Latina quanto no âmbito internacional. Reflexos desse processo incluem o reconhecimento do caráter multiétnico, pluricultural e multilíngue dos países latino-americanos, que se encontra presente nas constituições de muitos desses países, redigidas entre os anos 1980 e 1990. Abrangem também a proliferação de políticas públicas que passaram a valorizar as diferenças culturais, especialmente em áreas-chave como território, educação, saúde e patrimônio. Um exemplo particularmente relevante para a presente discussão está nos debates sobre interculturalidade, termo que emergiu na América Latina no contexto educacional, mais precisamente com referência à educação escolar indígena,

3 Para um dossiê recente que engloba trabalhos que abordam o encontro de saberes pensado nesses termos mais amplos, ver Barbosa Neto, Rose e Goldman (2020). 
paralelamente ao fortalecimento dos movimentos indígenas a partir da década de 1980 - ver, entre outros, Candau e Russo (2010) e Candau (2010)4.

A inclusão do conhecimento dos mestres e mestras de comunidades tradicionais nas universidades é importante, entre outros aspectos, porque possibilita romper com a monoepistemologia que em geral caracteriza os meios acadêmicos no Brasil. Ao mesmo tempo, essa inclusão propicia um questionamento do caráter eurocêntrico das universidades brasileiras, bem como o diálogo com as lógicas, racionalidades e cosmovisões indígenas e africanas, que costumam ser confinadas à condição de objetos de estudos antropológicos (CARVALHO, 2010). Outro objetivo importante do Encontro de Saberes, que ressoa com discussões contemporâneas da antropologia e outros campos da ciência, é buscar uma aproximação simétrica entre os saberes acadêmicos e aqueles provenientes de outros modos de experimentar e conhecer o mundo, em especial os das matrizes indígenas e afrodescendentes, colocando a ciência em intenso diálogo com um manancial de conhecimentos historicamente invisibilizados (BRASIL et al., 2014; GUIMARÃES et al., 2017).

A partir de 2014, a proposta do Encontro de Saberes começou a crescer e atualmente abrange pelo menos 13 universidades públicas no país, além de duas instituições internacionais ${ }^{5}$, o que sugere uma tendência de consolidação e de expansão dessa proposta (CARVALHO; VIANNA, 2020). Segundo dados sistematizados recentemente, até o ano de 2020 estas iniciativas contaram com a participação de 155 mestres e mestras das mais diversas culturas e regiões do país; 120 professores e professoras de diferentes áreas do conhecimento acadêmico; e abrangeram mais de 3.000 alunos e alunas (incluindo graduação, pós-graduação e extensão), totalizando cerca de quatro mil horas de carga horária (CARVALHO; VIANNA, 2020). Na Universidade Federal de Minas Gerais (UFMG), essa iniciativa teve início em 2014 por meio de um projeto piloto e foi oficializada em 2015 por meio da Pró-Reitoria de Graduação (PROGRAD), tornando-se a Formação Transversal em Saberes Tradicionais. Desde então, esse programa conta com uma oferta semestral regular de disciplinas, que são abertas para alunos e alunas de todos os cursos de graduação ${ }^{6}$.

Isabel de Rose participou entre 2014 e 2017 como colaboradora do Comitê Gestor da Formação Transversal em Saberes Tradicionais, tendo acompanhado diversas disciplinas como professora parceira. Ela também foi responsável por fazer o convite para Alcindo

\footnotetext{
4 Não é nosso objetivo aqui aprofundar esta questão. Em suma, é possível dizer que tanto a categoria de interculturalidade quanto o debate sobre este tema foram constituídos na América Latina a partir principalmente dos movimentos indígenas e afrodescendentes e de lutas, práticas e processos que questionam os legados eurocêntricos e os processos de homogeneização cultural - ver, entre outros, Candau e Russo (2010), Candau (2010), Walsh (2010) e Montardo e Rufino (2017).

5 De acordo com José Jorge de Carvalho e Letícia Vianna (2020), as universidades situadas no Brasil são: Universidade de Brasília (UnB), Universidade Federal de Minas Gerais (UFMG); Universidade Federal de Juiz de Fora (UFJF); Universidade Estadual do Ceará (UECE); Universidade Federal do Pará (UFPA, campus de Belém e Bragança); Universidade Federal do Sul da Bahia (UFSB); Universidade Federal do Rio Grande do Sul (UFRGS) e Universidade Federal do Cariri (UFCA); Universidade Federal do Vale do Jequitinhonha e Mucuri (UFVJM); Universidade Federal Fluminense (UFF); Universidade Federal do Rio de Janeiro (UFRJ); Universidade Federal de Roraima (UFRR); Universidade da Integração Internacional da Lusofonia Afro-Brasileira (UNILAB) (Carvalho e Vianna, 2020). Já as instituições internacionais são a Universidade de Música de Viena, Áustria, e a Pontificia Universidade Javeriana de Bogotá, na Colômbia.

6 Entre 2014 e 2019, esta formação ofereceu 23 disciplinas, contando com a colaboração de mais de 40 mestres e mestras das mais diferentes culturas e regiões do Brasil. Para mais informações, consultar http://www.saberestradicionais.org/.
} 
Wherá Tupã e Geraldo Karaí Okenda ministrarem um dos módulos da disciplina "Curas e cuidados" em 2015, motivada por sua interlocução prévia com eles durante a pesquisa de campo realizada na aldeia Yynn Morothi Wherá entre 2006 e 2008.

\section{Os Guarani no Sul do Brasil e a Trajetória de Alcindo Wherá Tupã e de Rosa Poty Djá ${ }^{7}$}

Os Guarani mbyá e chiripá que vivem no Sul e Sudeste do país totalizam cerca de 10 mil indígenas ${ }^{8}$. Eles formam uma rede de aldeias que são, ao mesmo tempo, cercadas pela crescente ocupação não indígena e conectadas entre si por laços de parentesco, trocas e práticas xamânicas. Mais recentemente, esses laços envolvem também articulações políticas relacionadas a demandas por território e por políticas públicas (PIMENTEL et al., 2010; MACEDO, 2010).

Ao longo da história desse povo, a manutenção da língua nativa, do corpus mitológico e das práticas espirituais tradicionais tem funcionado como importante estratégia de resistência. A família extensa constitui a referência básica da unidade política, econômica e espiritual nas aldeias guarani e consiste na unidade da reprodução social e biológica por meio da reciprocidade. Ela é formada por várias famílias nucleares, que se relacionam entre si por meio de um par comum de progenitores comuns, ou "avós". Estes geralmente atuam como "líderes espirituais" (karaikuery) e têm atributos xamânicos (CICCARONE, 2004). Um lugar central nas aldeias são as opy ou casas de reza, em que o karaí (líder espiritual) e sua companheira (cunhá karaí) realizam os rituais noturnos de reza, canto e dança que são fundamentais para manter a saúde individual e coletiva da comunidade ${ }^{10}$.

Até a segunda metade do século XX, a presença dos Guarani no Sul e Sudeste do Brasil foi pouco visível, e eles frequentemente usavam as estratégias de invisibilidade ou mimetismo, buscando desaparecer e/ou parecer com os não indígenas (ASSIS; GARLET, 2004). Foi principalmente a partir da década de 1970 que aconteceu uma mudança significativa no que diz respeito às suas estratégias, marcada por uma maior abertura para estabelecer diálogos com os não indígenas. No Estado de Santa Catarina, a presença e a visibilidade guarani começaram a aumentar durante a segunda metade do século XX, quando várias famílias extensas indígenas passaram a reocupar áreas que

\footnotetext{
Esta seção encontra-se em grande medida baseada na tese de Isabel de Rose (ROSE, 2010) e em um conjunto de textos escritos em coautoria com Esther Jean Langdon - ver, entre outros, Langdon e Rose (2012; 2014) e Rose e Langdon (2013).

8 Partindo de uma classificação baseada principalmente nas diferenças linguísticas, Egon Schaden (1974) propôs uma divisão dos Guarani em três subgrupos: kaiowá, mbyá e nhandeva. Atualmente, embora essas categorias continuem sendo uma referência importante, muitos pesquisadores vêm questionando essa classificação e apontando para a complexidade da divisão dos subgrupos guarani - ver, entre outros, Bartolomé (2008), Assis e Garlet (2004) e Mello (2006).

9 Os termos karaí, karaikuery no plural, ou o feminino cunhá karaí, são muitas vezes considerados equivalentes ao termo "xamã". Como veremos, Geraldo frequentemente se refere aos karaikuery como "líderes espirituais", e tanto ele quanto seu Alcindo também os definem como "médicos tradicionais". Em suma, os karaikuery atuam como protetores dos seus parentes e dos humanos em geral, trabalho que é realizado por meio da comunicação com os diferentes mundos e seres que constituem o cosmos, e que ocorre principalmente durante os sonhos, as visões e os rituais (MELLO, 2006).

10 A opy constitui o lugar de convergência de toda a aldeia e um contexto aglutinador de pessoas. As cerimônias de reza, canto e dança têm entre seus principais objetivos a produção de boas condições de vida, como saúde, alegria e fortalecimento (CICCARONE, 2001; PISSOLATO, 2007).
} 
fazem parte de seu território tradicional (DARELLA, 2004). Esse movimento refletiu no aumento do número de aldeias e na intensificação da ocupação guarani nessa região (DARELLA, 2004).

Em suma, podemos dizer que as comunidades guarani no Sul e Sudeste do Brasil emergiram da invisibilidade cultural que em geral os caracterizou até os anos 1990 por meio de uma série de iniciativas criativas que incluíram o aumento da agência política, que se expressa, entre outros aspectos, na criação de uma série de organizações políticas indígenas a partir do início dos anos 2000; e a entrada no mundo dos eventos e produtos culturais, principalmente por meio dos corais de crianças e da gravação de CDs e DVDs com os cantos tradicionais (MACEDO, 2010; 2011). Por outro lado, a maioria das aldeias nessa região ainda não tem seu território legalmente demarcado, e a população guarani em geral continua tendo um lugar marginalizado. Somado a isso, os mbyá e chiripá carregam o estigma de "índios aculturados" e são frequentemente considerados como errantes ou nômades (LADEIRA, 2007).

Fazendo parte desse movimento de reocupação dos territórios tradicionais guarani, Alcindo Wherá Tupã Moreira e Rosa Poty Djá Mariano Cavalheiro chegaram em Santa Catarina no final dos anos 1980 com seus filhos e familiares, vindo do Sul numa migração inspirada por sonhos xamânicos. Eles se fixaram na aldeia Yynn Morothi Wherá, ou M'biguaçu, localizada no município de Biguaçu e situada a cerca de 30 km de Florianópolis, a capital de Santa Catarina. Essa aldeia foi demarcada em 2003, com 59 hectares, tendo sido a primeira Terra Indígena guarani oficialmente reconhecida nesse estado.

Alcindo e Rosa são amplamente conhecidos e respeitados na rede das aldeias guarani do Sul e Sudeste do Brasil como curadores e líderes espirituais dotados de grandes poderes e conhecimento (MELLO, 2006). Nascidos nos anos de 1920, eles passaram grande parte de sua vida adulta migrando de um lugar para outro nos Estados do Paraná, Santa Catarina e Rio Grande do Sul. Suas migrações foram muitas vezes motivadas por fatores que incluem o aumento da ocupação não indígena no território guarani e a violência que frequentemente resultou desse processo, e, durante alguns períodos de sua trajetória, eles chegaram a viver e a trabalhar entre não indígenas. Em 1987 eles se estabeleceram em M'biguaçu com o sonho de voltar a viver de acordo com o "modo de vida guarani", ou nhandereko (OLIVEIRA, 2011).

As características pessoais desse casal de anciões como lideranças espirituais e sua vida de migrações em busca do modo de vida guarani, que os levou a se fixarem por um longo período em $\mathrm{M}^{\prime}$ biguaçu, ${ }^{11}$ diferencia a eles e sua família extensa da maioria dos Guarani. Sua preocupação com a revitalização cultural se expressa, entre outros aspectos, por meio de uma série de iniciativas criativas empreendidas em áreas como saúde, educação e xamanismo. Três dos filhos de Alcindo e Rosa são professores bilíngues e se dedicam à alfabetização das crianças guarani. Geraldo Karaí Okenda, o segundo filho homem do casal, foi o primeiro professor bilíngue em M’biguaçu quando a escola foi implementada na aldeia em 1998. Ele também é graduado no curso de Licenciatura Intercultural Indígena do Sul da Mata Atlântica da Universidade Federal de Santa Catarina, especialmente

\footnotetext{
${ }^{11}$ No início de 2015, devido a disputas familiares e políticas, Alcindo, Rosa e parte de sua família extensa se mudaram para outra aldeia vizinha, a Reserva Indígena Amaral, ou Tekoa Mbyá Roká, também localizada no município de Biguaçu (SC). Infelizmente, Rosa Poty Djá faleceu em abril de 2019.
} 
criado para os povos indígenas desse estado. Geraldo é o principal assistente de Alcindo nos rituais realizados na casa de reza. Ele também é um dos principais mediadores nos contatos e negociações com os não indígenas e é um especialista na tradução de ideias e conceitos guarani para o público não indígena. Como veremos adiante, essas experiências prévias tiveram implicações interessantes em sua participação no Encontro de Saberes da UFMG.

A reocupação de M’biguaçu pela família de Alcindo e Rosa coincide com o início de um processo que os moradores dessa aldeia definem como sendo de "valorização da tradição", e que começou a se intensificar a partir dos anos 1990. Algumas iniciativas importantes nesse processo incluíram a criação do coral Yvychi Ovy (nuvens azuis) em 1996; a construção de uma casa de reza nova na aldeia em 1998; e a edificação da primeira escola bilíngue neste mesmo ano. Esse processo também esteve relacionado à retomada da realização frequente dos rituais noturnos de reza, canto e dança na casa de reza.

M’biguaçu, como outras aldeias do Estado de Santa Catarina, tem sido o foco do interesse de uma série de atores não indígenas, principalmente ao longo das últimas duas décadas, o que se reflete em uma série de investigações etnográficas recentes e também em diferentes projetos, desenvolvidos em parceria com ONGs e agências governamentais. Tudo indica que as lideranças guarani das aldeias da região estão rapidamente aprendendo a dialogar de maneira estratégica com essa rede de apoio e com o crescente interesse na cultura indígena por parte de certos setores da sociedade; em muitos casos, eles conseguem direcionar os benefícios que vêm desses diálogos para suas comunidades.

É dentro desse contexto mais amplo que podemos situar o papel da família extensa de Alcindo e Rosa na formação da rede da Aliança das Medicinas e a inclusão da bebida amazônica popularmente designada como ayahuasca ${ }^{12}$ como parte dos ritos noturnos de reza, canto e dança, realizados na casa de reza de M’biguaçu. Essa rede emergiu em Santa Catarina no final dos anos de 1990 com base nos diálogos estabelecidos entre os moradores dessa aldeia; a vertente brasileira do grupo xamânico internacional Fogo Sagrado de Itzachilatlan, também conhecido como Caminho Vermelho ${ }^{13}$; e uma comunidade do Santo Daime ${ }^{14}$. Em síntese, podemos dizer que o Fogo Sagrado do Brasil, essa comunidade do Santo Daime e os integrantes da família extensa de Alcindo e Rosa estão estreitamente vinculados em relações de influência mútua, formando uma rede que tem como um dos seus eixos centrais o interesse comum em torno da "medicina tradicional" e da "espiritualidade".

\footnotetext{
${ }_{12}$ Há muito tempo a ayahuasca (Banisteriopsis SP) tem sido associada com o xamanismo ameríndio e com a medicina tradicional indígena. Ao longo das três últimas décadas, os usos desta bebida têm se expandido para fora da região amazônica, entre populações urbanas nas mais diferentes partes do mundo. Nessas redes urbanas ligadas ao universo da Nova Era, a ayahuasca circula como uma substância xamânica pan-indígena e costuma ser associada a ideias como espiritualidade, cura holística e autoconhecimento - ver, entre outros, Labate e Cavnar (2014).

13 O Fogo Sagrado de Itzachilatlan foi fundado nos Estados Unidos nos anos 1980 e posteriormente se expandiu para vários países latino-americanos e para a Europa. Seus rituais são inspirados na Igreja Nativa Norte-Americana, uma religião pan-indígena que teve início no século XIX e é conhecida pelo uso ritual do cacto peiote (Lophophora williamsii), e em outras práticas dos grupos indígenas norte-americanos, especialmente dos Lakota - para mais informações, ver, entre outros, Rose (2010) e Rose (2019).

14 O Santo Daime, uma das religiões ayahuasqueiras brasileiras, foi criado no Acre entre os anos 1930 e 1960 inspirado por experiências visionárias dos seus líderes carismáticos com a ayahuasca. A partir dos anos de 1980 se expandiu por todo o Brasil e nos anos de 1990 para outras partes do mundo - ver, entre outros, Labate e Araújo (2004).
} 
A introdução do uso da ayahuasca, na aldeia Yynn Morothi Wherá teve como ponto de partida a elaboração de um projeto no final dos anos 1990, tendo como protagonistas centrais os membros da família extensa de Alcindo e Rosa, lideranças nacionais do Caminho Vermelho e funcionários da Equipe Multidisciplinar de Saúde Indígena (EMSI) que atendia às aldeias da região. Esse projeto tinha como principais objetivos fortalecer a "medicina tradicional", a transmissão dos conhecimentos xamânicos e a formação de novas gerações de lideranças espirituais indígenas entre os Guarani no Sul do país. Com base no conceito de "medicina tradicional", que constitui um eixo central da Política Nacional de Atenção à Saúde dos Povos Indígenas (PNASPI), essa iniciativa foi financiada pela FUNASA durante quatro anos, resultando na implementação de um conjunto de práticas rituais, incluindo o uso da ayahuasca, em pelo menos dez aldeias guarani no Sul do Brasil. Entretanto, sua aceitação não foi consensual e muitos indígenas rejeitaram a proposta como sendo "coisa de brancos". Na aldeia Yynn Morothi Wherá, houve uma adesão mais ampla, respaldada pela liderança de Alcindo e Rosa, e essas práticas foram reconhecidas como "medicinas tradicionais guarani". Na época da pesquisa de campo conduzida por Isabel de Rose no final dos anos 2010, muitos moradores dessa aldeia consideravam que essas práticas tinham sido importantes para lidar com uma série de problemas que a comunidade vinha enfrentando, como desorganização social e alcoolismo, bem como para revitalizar a vida ritual coletiva e o sistema xamânico. Por outro lado, é fundamental levar em conta a heterogeneidade, a falta de consenso, bem como os equívocos e limites envolvidos nesse processo, tanto no que diz respeito aos atores não indígenas quanto entre os próprios Guarani ${ }^{15}$.

Esse movimento de valorização da cultura protagonizado pelos integrantes da família extensa de Alcindo e Rosa faz parte de um processo mais amplo de revitalização cultural que vem sendo empreendido pelos Guarani do Sul e Sudeste do Brasil por meio de estratégias que incluem a educação bilíngue, a promoção de performances culturais e a realização de projetos de autossustentabilidade e resgate de conhecimento - ver, entre outros, Macedo (2010). No caso específico da família extensa de Alcindo e Rosa, o interesse dos integrantes do Santo Daime e do Fogo Sagrado nos povos e conhecimentos indígenas, em geral, e nos Guarani, em particular, também fez parte desse processo. Esse interesse é motivado por imagens comuns nesses grupos e no amplo e diverso movimento designado com Nova Era, como as do "indígena espiritual" ou "ecológico", da "sabedoria primordial", do "resgate do passado" e da "medicina indígena" (LANGDON; ROSE, 2012; ROSE; LANGDON, 2013).

Como veremos na próxima seção, essas imagens aparecem nas falas de seu Alcindo e, principalmente, nas de Geraldo durante as aulas que eles ministraram na UFMG. Consideramos que a forma como eles agenciam essas imagens dentro desse contexto constituem um exemplo de como as lideranças indígenas muitas vezes fazem uso de representações como essas de forma reversa e criativa, empregando-as de maneira a atender às suas próprias reivindicações e interesses. Pensamos que é possível sugerir que o uso criativo dessas imagens e conceitos encontra-se ligado em parte ao trânsito dessas

\footnotetext{
15 Por questões de recorte e de espaço, não pretendemos nos aprofundar nesta discussão aqui. Para maiores informações sobre o uso da ayahuasca na aldeia Yynn Morothi Wherá - ver, entre outros, Rose (2010), Langdon e Rose (2012; 2014) e Rose e Langdon (2013).
} 
lideranças indígenas em redes xamânicas contemporâneas, como é o caso da Aliança das Medicinas, mas também em outros espaços de trocas e diálogos entre diferentes sistemas de conhecimento, como o Encontro de Saberes. Desse modo, essas reinvenções criativas têm implicações em múltiplas direções.

O intercâmbio de conhecimentos xamânicos como parte das redes de troca na América do Sul está longe de ser uma novidade. Estudos realizados no Peru, Colômbia, Equador e Brasil documentaram redes xamânicas que, desde os tempos pré-coloniais, acompanham as rotas de comércio, ligando os grupos indígenas das Terras Baixas entre si e também com os grupos das Terras Altas andinas - ver, entre outros, Chaumeil (1992) e Langdon (2012). Somado a isso, pesquisas sobre as trocas entre grupos indígenas e seus vizinhos "mestiços" ou "caboclos" indicam que o fluxo de influências nessas redes nunca foi unidirecional - ver, entre outros, Gow (1994). Entretanto, desde os anos 1980 , as redes xamânicas passaram a conectar os xamãs indígenas também a outros circuitos, mais amplos e que incluem diferentes grupos e atores não indígenas. Esse fenômeno emergente envolve contínuos deslocamentos de larga escala de especialistas rituais e de praticantes; forte presença na internet; e entrecruzamentos e reconfiguração de discursos e práticas, criando novas formas de itinerância ou novas redes (LOZONCZY; MESTURINI, 2010).

A pesquisa de Isabel de Rose sobre a Aliança das Medicinas foi uma das primeiras investigações sobre o atual processo de entrada de indígenas brasileiros nos circuitos da Nova Era e da ayahuasca (ROSE, 2010). Especialmente ao longo dos últimos 15 anos, os rituais indígenas direcionados para um público urbano e de classes média e alta conduzidos nas grandes cidades em diferentes partes do país estão crescendo. Ao mesmo tempo, vêm se multiplicando os festivais culturais realizados nas aldeias indígenas - principalmente na Amazônia, mas também em outras regiões - e que são voltados especialmente para participantes não indígenas - ver Labate e Coutinho (2014). Como consequência, os intercâmbios e as alianças entre grupos indígenas e grupos espirituais não indígenas também estão aumentando, bem como as pesquisas sobre essas redes xamânicas contemporâneas ${ }^{16}$. Embora esse seja um processo recente, essa tendência está apenas crescendo e está transformando profundamente os circuitos da Nova Era e da ayahuasca, tanto no Brasil quanto no exterior.

\section{Xamanismos Guarani Contemporâneos no Encontro de Saberes}

Nesta seção enfocamos a análise do material do módulo da disciplina "Curas e cuidados", ministrado por Alcindo Wherá Tupã e Geraldo Karaí Okenda na UFMG em maio de 2015 para uma turma de 40 alunos e alunas. Esse módulo foi composto de quatro aulas, de cerca de quatro horas cada uma. As aulas aconteceram em salas de

\footnotetext{
${ }^{6}$ Entre outros exemplos recentes dessa tendência encontra-se a chegada da ayahuasca entre os Yudjá no Alto Xingu, processo inicialmente intermediado por uma equipe médica ligada à União do Vegetal, uma das religiões ayahuasqueiras brasileiras (STOLZE LIMA, 2018). Segundo Tânia Stolze Lima (2018), o contato entre os Yudjá e esta bebida contribuiu para impulsionar a pajelança e para ativar a transmissão de conhecimentos xamânicos entre as velhas e novas gerações.
} 
aula convencionais e também ao ar livre na Estação Ecológica da UFMG ${ }^{17}$. Elas foram marcadas pelas falas de Alcindo e Geraldo e por rodas de perguntas com os alunos e alunas. Também foram caracterizadas por cantos guarani e pela fumaça do tabaco (fumado nos petynguás ou em cigarros de palha) ${ }^{18} \mathrm{e}$ do fogo que seu Alcindo fez questão de sempre ter aceso nas aulas ao ar livre. Outro aspecto muito importante foram os momentos de silêncio, que apontavam para um outro modo de lidar com a palavra e com o próprio conhecimento. Os silêncios, a falta de um início e um final claramente demarcados, a aparente informalidade, os temas e questões abordados, entre outros aspectos, contribuíram para evidenciar a relação com a alteridade. Tratava-se claramente de um tipo de aula não convencional no contexto da universidade, o que gerava interesse, mas também causava incômodos e inquietações entre os alunos. As aulas foram gravadas e filmadas, depois foram posteriormente transcritas na íntegra. A estratégia para abordar este material foi selecionar alguns temas-chave que aparecem nas falas de seu Alcindo e Geraldo e procurar agrupar o material de acordo com esses temas. Paralelamente, apontamos como essas falas se relacionam com aspectos centrais da cosmologia e do sistema xamânico guarani.

No caso das falas de Alcindo, os principais temas abordados incluíram: a importância de se lembrar de Nhanderu ${ }^{19}$ e da oração; comentários sobre seu processo de aprendizado xamânico, contando sobre como aprendeu com seu pai, que era "um médico dos guarani", e envolvendo comparações entre o próprio conhecimento e o conhecimento dos médicos não indígenas; a importância do petynguá (cachimbo guarani) e do tabaco nesse processo de aprendizado, envolvendo uma comparação entre o petynguá e a Bíblia, e trazendo implícita também uma comparação entre sistemas de conhecimento distintos; a importância do cuidado com a alimentação e suas implicações na saúde, envolvendo também uma comparação entre a alimentação indígena "de antigamente" ("tradicional") e a alimentação atual, tanto indígena quanto não indígena; uma ênfase em como eram as coisas "antigamente", ressaltando que nessa época não existiam doenças, médicos ou escola; e um destaque para a importância dos pais, da família, das pessoas mais velhas e de seu conhecimento, em especial para orientar os mais jovens.

Como vimos, Geraldo pode ser considerado como um especialista em traduzir ideias e conceitos indígenas para o público não indígena, o que possivelmente se relaciona com sua trajetória como professor e educador bilíngue e, também, como pesquisador indígena. Por fazer parte de outra geração, ele está mais familiarizado com o português e domina melhor os códigos implícitos nas interações com os não indígenas. Assim, em muitos

\footnotetext{
${ }_{17}$ A Estação Ecológica da UFMG é uma unidade de conservação, pesquisa e educação ambiental situada dentro do campus, que atua como parque e escola e que conta com muito espaço verde.

18 De acordo com Pissolato (2007, p. 352), o tabaco constitui o principal “[...] meio de aquisição de conhecimento divino e instrumento de proteção fornecido pelos deuses [...]", sendo sua fumaça "[...] o veículo por excelência do conhecimento-poder que o xamã pode 'passar' para os demais". O pety ou tabaco é "[...] uma planta de grande importância cosmológica, fundamental na maioria dos rituais xamânicos" (MELLO, 2006, p. 231). Fumado no petynguá, ele funciona como "um escudo para os humanos" (MELLO, 2006, p. 231), sendo que sua fumaça é fundamental para produzir o estado de neblina, quando os karaikuery conseguem fazer contato com outros planos (MELLO, 2006, p. 231-32). Somado a isso, sua fumaça “[...] confere a sabedoria necessária para se tomar as boas decisões e escolher os caminhos certos" (MELLO, 2006, p. 233).

19 Embora os mbya reconheçam uma variedade de divindades que são invocadas nas rezas e estão associadas a direções distintas no céu, na referência à relação com o divino, é comum falar-se de Nhanderu ou "nosso pai" de modo unificado (PISSOLATO, 2007, p. 58).
} 
momentos da disciplina, ele comentou e explicou as falas de seu Alcindo, procurando deixá-las mais claras para os alunos do curso. Somado a isso, temas recorrentes nas suas falas incluíram comentários sobre o próprio processo de aprendizado xamânico e sobre a importância da espiritualidade para os Guarani, relacionados com a questão enfatizada por seu Alcindo a respeito da importância da oração e de sempre lembrar de Nhanderu. Com relação ao processo de aprendizado do conhecimento indígena, reaparece outro tema enfatizado por seu Alcindo, a importância dos mais velhos, que são definidos por Geraldo como "uma biblioteca viva", tendo um papel fundamental na educação guarani e na transmissão do conhecimento. Esse aspecto se relaciona com a importância que ele dá à história e ao conhecimento oral, que são repassados de geração em geração, como forma de preservação e de continuidade do povo e da cultura guarani.

Selecionamos a seguir algumas dessas falas que abordam aspectos importantes do sistema xamânico guarani, incluindo o processo de aquisição do conhecimento xamânico.

Olha, no tempo do paizinho [...] era um médico, viu, um médico dos Guarani. Então, quando eu tinha sete anos eu era curioso, viu. Parece que eu queria aprender, [...]. Enquanto o paizinho estava vivo, ele dizia "ó filhinho, tu quer [aprender]? Então vamos, vamos!". Aí nós íamos na floresta. Cada madeira, cada medicina que chegava [que a gente encontrava], ele dizia: "essa aqui é uma madeira para aquele problema" [...]. Então [eu] colocava na cabeça [...]. Eu estava estudando. É a mesma coisa, como vocês [...]. Então, tudo isso eu coloquei na cabeça [...]. Na minha família só eu que queria saber, "Ah filhinho" [meu pai dizia], "tem que estudar até que chegar lá, viu...". Graças a Deus, ele [indicando o Geraldo] e o Wanderlei [seu outro filho, mais novo] estão aprendendo, viu. Estão repartindo minha sabedoria. Um dia eu vou embora, né... Que todos nós aqui ficamos para semente; um dia a gente vai embora. Mas pelo menos podemos deixar essa lembrança para nossos parentes, né... Então, eu sei que no final eu aprendi, aprendi do paizinho mesmo. Aprendi tudo, viu. Graças a Deus! [...].

É por isso que muitos lá em Santa Catarina me respeitam, [dizem] você é o médico dos Guarani mesmo... Qualquer problema que as pessoas têm, elas chegam do meu lado, eu já sei como é que é, né... Só que eu explico, porque um chazinho é natural, não mata, né... E o médico de vocês, todo engravatado, empacotadinho, para combater os problemas de vocês tem que tomar várias garrafinhas [remédios], meu Deus! [...] Já com esse [remédio] natural, tomou, curou, [a doença] não volta mais... A minha história é essa aí, viu [...].

(Alcindo Wherá Tupã, aulas ministradas na UFMG em maio de 2015)

Então, vocês entenderam como é a relação entre a espiritualidade com a nossa vida [...]. É porque a educação indígena, principalmente guarani, nós somos da etnia Guarani, a educação já vem desde criança. É ensinado dessa maneira. Por exemplo, a respeitar. De que maneira é repassado o conhecimento do pai para o filho, da mãe para a filha. Então ela [a educação] já vem desde o início. Quando [a pessoa] chegar na puberdade ela já se transforma, é transformada, para que possa também repassar o conhecimento para o próximo. Então, tudo isso é um relacionamento que a gente repassa para os nossos filhos, através da educação, através da alimentação, através dos conhecimentos dos mais velhos [...]. Porque os mais velhos para nós são uma biblioteca viva. Eles estão sempre formando, sempre orientando de que maneira que a gente caminha na nossa vida. Porque o seu Alcindo sempre fala que o caminho que ele percorreu os mais novos que estão vindo atrás vão percorrer também, mas de outro jeito. Porque o mundo de hoje é diferente que o dos antigos. Então, ele orienta como a gente pode viver. De maneira que a gente possa estar mais tranquilo nessa caminhada da nossa vida [...]. (Geraldo Karaí Okenda, aulas ministradas na UFMG em maio de 2015) 
Um dos aspectos centrais abordados nas falas transcritas acima é o processo de aquisição do conhecimento entre os Guarani, em particular o conhecimento xamânico, ou o conhecimento relacionado com a "espiritualidade", seguindo a definição de Geraldo. Seu Alcindo e Geraldo definem os karaikuery como "líderes espirituais" e como "médicos tradicionais", ressaltando seu papel como dirigentes das cerimônias realizadas na casa de reza e também suas habilidades de cura. Geraldo enfatiza ainda a conexão dos karaikuery com Nhanderu, que se manifesta em capacidades como os conhecimentos sobre a "Mãe Terra" e o céu, e a habilidade para dar nomes às crianças ${ }^{20}$ (Geraldo Karaí Okenda, entrevista realizada em 2008).

Transcrevemos a seguir falas a respeito de outro tema, também relacionado ao xamanismo, que foi recorrente nas aulas, em especial nas narrativas de seu Alcindo: a importância do petynguá e do tabaco; e seu papel no processo de aprendizado xamânico e na obtenção de conhecimento. Como vemos, o cachimbo guarani é comparado por Alcindo a uma Bíblia, ao mesmo tempo que ele aponta para as diferenças entre os conhecimentos que adquire assim e os conhecimentos não indígenas presentes na Bíblia escrita no papel. Novamente, essa fala é seguida por um comentário de Geraldo, que busca explicar as ideias colocadas por Alcindo de uma maneira mais acessível para os alunos não indígenas da disciplina. Assim, ele atualiza as comparações sugeridas por Alcindo, propondo que o petynguá funciona como um "celular indígena", por meio do qual é possível se conectar com o Grande Espírito.

Eu acho que vou contar só um pedacinho. Então, minha Bíblia já é diferente, viu. Minha Bíblia não é dessa aqui [de papel]. Acho que você sabe, né... Minha Bíblia é diferente [...]. São aqueles [lá de cima] que me dão ensinamentos, viu... É no sonho mesmo: vai por aqui, não vai nessa [direção] aqui. Eu já não vou... O petynguá, aquilo é minha Bíblia, viu. Trazem ensinamentos... Como vocês brancos eu uso tabaco também, mas eu sei usar [...]. Então minha Bíblia já conta. No sonho mesmo conta o que vai acontecer, o que já aconteceu [...].

Esse aqui é a minha Bíblia... Esse aqui é que me dá o ensinamento, de como foram as coisas, como existe a água, de onde as coisas começaram. Minha prova é essa... Então esse aqui é que me deu o ensinamento, de como antigamente se vivia. Naquele tempo não tinha doença mesmo. A hora que eu estou trabalhando coloco tabaco aqui [apontando para o petynguá], coloco aqui o tabaco, queimo ele... Ele [Nhanderu] está junto conosco aqui, nós não estamos enxergando. Parece que nós estamos sozinhos, mas não, ele que está [nos] levando. Aonde é nosso caminho, [ele] tá indo junto. Nós não estamos enxergando. Então eu coloco o tabaco aqui, eu puxo ele, ele [Nhanderu] entra aqui, tá aqui a escadinha dele [apontando para um detalhe no petynguá]. Ele entra aqui, eu puxo ele, então eu solto as maldades, as perturbações. Mas eu tenho que acreditar aqui [apontando para o próprio peito]... A gente não enxerga, viu. Ele está junto com a gente. Aonde é seu caminho [ele] está indo junto, viu... É por isso que a gente deve, quando a gente sair, parar mais ou menos meio minuto $e$ orar para Ele, pedir... Na hora que a gente tropeça, aí [ele pergunta] "ó filhinho, porque que não se alembrou de mim?" Por que nós não estamos enxergando nosso caminho. Às vezes tem uma pedrinha e a gente não enxerga. Então, essa é minha sabedoria, graças a Deus! Esse aqui [meu petyngua] me avisa, viu. Esse aqui me avisa, fala para mim... Me avisa dos problemas que vão acontecer... Mas não é igual a gente de carne e osso [trecho editado], a

\footnotetext{
${ }^{20}$ A pessoa mbyá é formada por duas "almas" ou "essências vitais" principais, uma de origem divina e outra de origem animal. O primeiro é o nhe'e, a alma enviada dos planos cósmicos superiores pelos deuses protetores dos humanos. Já o segundo, o $a^{\prime} \tilde{a}$, representa a parte mundana da alma, ligada ao corpo, ao sangue e à carne, sendo perecível e sujeita à contaminação (MELLO, 2006). O nhe'e encontra-se estreitamente relacionado com o nome guarani, que é visto, sonhado ou recebido pelos karaikuery e proclamado no nhemongarai, ritual durante o qual ocorre a nominação das crianças e o batismo do milho (MELLO, 2006; PISSOLATO, 2007).
} 
gente não enxerga, não. Então, na hora que me avisa: "ó filhinho, tu não vai pra roça, tem um perigo". Então eu já fico, já não vou... Então, esse aqui me avisa.

(Alcindo Wherá Tupã, aulas ministradas na UFMG em maio de 2015)

Porque na tradição guarani é muito usado esse cachimbo, cachimbo de barro. Ele [o seu Alcindo] sempre fala, dá um exemplo de Bíblia. Esse que a gente chama de petynguá, que é o cachimbo, ele traz todas as informações, traz proteção e faz cura também. A gente coloca esse pety, tabaco, com um propósito. No momento que a gente vai usar esse cachimbo também usa o tabaco. O tabaco é uma palavra que a gente está colocando, um propósito dentro desse cachimbo. No momento que é acendido esse tabaco, são puxadas todas as informações, o desejo que tem dentro do seu coração, para que possa levar com essa fumaça até o Grande Espírito. Então, é tipo um celular, um celular indígena. É mais rápido e não precisa carregar. Então o seu Alcindo usa muito isso. Ele está me repassando todo seu conhecimento, sua sabedoria. o processo de espiritualidade. Eu me dediquei com isso. Eu estou aprendendo há mais de 25 anos com ele [...]. Então, esse nosso petynguá, como a gente chama o cachimbo, ele traz toda a harmonia. Isso depende do propósito que a gente vai colocar. A gente reza com esse cachimbo, faz cura. Principalmente o seu Alcindo faz cura com ele. É o raio-X dele [...]. Ele éo Guarani mais velho da tribo guarani. E ele é conhecido em toda a etnia, principalmente dos Guarani, do Rio de Janeiro até o Rio Grande do Sul. E ele lê muito pensamento, ele gosta de ler os pensamentos dos outros. Ele vê no momento que a pessoa está passando uma dificuldade, ou até mesmo está com [um problema] de saúde. Ele pega, só olha, e [sabe], "você tem essa doença". [...]. Às vezes a gente só pensou e ele já fala [o que estamos pensando]. Então, é através desse cachimbo que ele consegue buscar as informações, e repassa para nós também.

(Geraldo Karaí Okenda, aulas ministradas na UFMG em maio de 2015)

Nessas falas aparecem vários aspectos que são centrais na cosmologia e no sistema xamânico guarani, incluindo a importância conferida aos sonhos e ao papel do tabaco. Ao longo das últimas duas décadas, várias etnografias têm indicado a importância dos sonhos para os Guarani, sugerindo que estes estão relacionados às atividades de reza e cura. Os sonhos também são considerados como mensagens divinas, e sua narração é valorizada (PISSOLATO, 2007). Ver em sonhos põe a pessoa em comunicação com outros mundos e seres, e a realidade vista nos sonhos têm o poder de interferir no plano da realidade cotidiana (MELLO, 2006). Nesse sentido, é frequente que os saberes relacionados ao xamanismo e à feitiçaria se manifestem nos sonhos, que remetem aos outros mundos. Assim, é no sonho que o karaí adquire seus poderes de adivinho, curador e dirigente cerimonial. É nos sonhos que ele recebe a revelação dos cantos, por meio dos quais se comunica com as divindades (CICCARONE, 2001, p. 186). Somado a isso, é no sonho que o karaí viaja para outros mundos, e também é pela experiência do sonho que se processa sua iniciação. A interpretação do conteúdo dos sonhos, uma das funções importantes dos karaikuery ("xamãs") guarani, influi tanto nas atividades cotidianas como nas decisões importantes (MONTARDO, 2009), propiciando um guia para a existência (CICCARONE, 2004).

Entre os Guarani, o tabaco é central para a realização de todos os atributos e atividades dos karaikuery e aparece como uma planta de uso indispensável, bem como o petynguá, instrumento ritual usado para fumá-lo. Como vemos nas falas de Alcindo e Geraldo transcritas acima, o petynguá e o tabaco têm um papel importante na cura e também são usados como uma forma de se concentrar e rezar. Para Geraldo, o pety (tabaco) e o petynguá (cachimbo) podem ser considerados, respectivamente, como o "alimento 
da palavra" e o "centro da palavra" (Geraldo Karaí Okenda, entrevista realizada em 2008). Em suma, o tabaco constitui um instrumento fundamental para a realização das atribuições dos karaikuery, entre as quais se encontram a cura; a comunicação com os deuses e a intermediação entre eles e os humanos, o que inclui a direção das cerimônias; e a interpretação dos sonhos.

Sugerimos anteriormente que a atuação de Geraldo como "tradutor" das falas de seu Alcindo possivelmente se relaciona com sua trajetória como professor e pesquisador indígena. Entretanto, somado a isso, essa capacidade também pode ser pensada em relação ao seu papel como aprendiz xamânico. Nos estudos clássicos sobre xamanismo, o termo "xamã" costuma ser associado à função de tradução e mediação entre os diferentes mundos e planos que compõem os cosmos, e entre os diversos seres que habitam esses mundos - ver, entre outros, Chaumeil (1998), Langdon (1996) e Langdon (2015). Existem também trabalhos que apontam que no contexto atual os xamãs atuam muitas vezes como mediadores entre os mundos e discursos indígenas e não indígenas, e como tradutores do conhecimento indígena nas negociações com o chamado "mundo não indígena" (ALBERT, 2002; CARNEIRO DA CUNHA, 2009; KOPENAWA; ALBERT, 2010). Ainda nesse sentido, recentemente Tânia Stolze Lima (2018) sugeriu que as associações entre os xamãs e as lideranças indígenas especializadas nas conexões com "os de fora" podem atuar de modo a fazer da política indígena um dos modos de existência do xamanismo. Cabe apontar, entretanto, que essas operações de tradução e conexão implicam em estabelecer relações entre conceitos que partem de pressupostos ontológicos radicalmente diferentes. Desse modo, elas frequentemente esbarram em limites e equívocos - ver Viveiros de Castro (2004).

Outra discussão muito interessante levantada por Geraldo nas aulas, e possivelmente relacionada com sua própria experiência, tanto como professor e pesquisador indígena quanto como aprendiz xamânico, aparece nas várias comparações que ele propõe entre o conhecimento indígena e a universidade, e os processos de aprendizado envolvidos nos dois casos. Somado a isso, várias vezes ele também afirmou que os Guarani mais jovens frequentemente precisam transitar entre "dois mundos", indígena e não indígena, e fazer mediações entre dois sistemas de conhecimento distintos. Além da espiritualidade, outro aspecto, relacionado com este, ressaltado por Geraldo como sendo importante para a sabedoria indígena, é o conhecimento da natureza. Optamos por transcrever a seguir um trecho longo de uma de suas falas nas aulas, no qual ele discute estes temas. Consideramos que esta fala evidencia por si mesma a capacidade de Geraldo como tradutor, em múltiplos planos, e ao mesmo tempo a criatividade presente nas suas narrativas, que transitam entre diferentes registros de saberes.

Então, nesse momento a gente está unido, para que possamos levantar esse conhecimento, dentro de nós mesmos, e ter relação com a natureza, porque a gente faz parte dela. A natureza dá o ensinamento e repassa o ensinamento. Na cultura indigena, a mata é um livro, um livro botânico, e o céu um livro didático, principalmente as constelações. Que a gente vê bastante estrela, no inverno, principalmente. O caminho da anta, que a gente fala muito. Esse é um caminho que todo o conhecimento do Grande Ser, do Grande Criador, deixou para nós, observar o céu. Com ele a gente aprende a fazer as coisas, e dá o ensinamento. Então, é uma relação que nós todos temos, mas às vezes a gente esquece. Esquece porque o mundo de hoje é diferente que o dos antigos, então às vezes a gente esquece de nós mesmos [...]. O conhecimento dos 
anciöes faz parte de todas as relações. Por isso que a gente fala aguydjevete, ${ }^{21}$ tem alguns que conhecem aho mitakuye oyas'in. ${ }^{22}$ Essas palavras [querem dizer] todos por nossas relaçöes. Que a natureza, a gente faz parte dela também. Nós somos todos irmãos. As árvores, a água, os animais. A gente faz parte da família da natureza. E às vezes a gente se esquece mesmo de agradecer a natureza, que é a nossa vida também. No ensinamento dos ancióes, no momento que a gente aprende o caminho, a gente aprende a caminhar, ela repassa todas as informações. Na prática que a gente começa a aprender toda a nossa vida. As crianças, no momento que elas nascem elas já vêm com uma missão, já vêm com um propósito para continuar esse caminhar. A relação que a gente tem com a natureza é importante. Porque ela dá a vida para nós, e ela pede ajuda para nós também. Então é uma ligação que a gente tem. Por isso que tem que agradecer as árvores, a água, a cachoeira, principalmente. Porque no conhecimento indígena a cachoeira $e$ as árvores têm alma, tem um espírito, elas sentem também que falta a gente cuidar delas. É uma relação que a gente tem, [e temos que] repassar esse conhecimento. Principalmente os anciöes, os mais velhos, quando entram na mata, eles veem todos os espíritos. Conhecem as medicinas, conhecem todas as árvores, e eles conversam com as árvores, porque têm espírito. E quando morre, é porque o espírito já foi. Igual nós também: a gente vai crescendo, vai ficando velhinho, a gente morre também. E as árvores também. Elas não vivem muito tempo. Ela cresce, dá fruta, dá semente, e depois morre. O corpo físico. O espírito está no céu.

Então a relação entre o céu e a terra é importante para nós também, como a gente conhece. Porque a gente faz parte dela, e a gente nasce dela. Por exemplo, o nascimento da criança, quando vem, vem de um lugar. Às vezes vem do norte, vem do leste, oeste, do centro do universo... Então todos nós somos parte dessas estrelas, nós somos filhos do Grande Espírito. A gente que às vezes esquece [disso], a gente está perdido nesse mundo... A gente não pensa na espiritualidade; a gente pensa mais na matéria, não no espírito. E o conhecimento indígena não, conhece o espirito e conhece o material. Então, tudo é um relacionamento que a gente tem, [entre] o céu, a terra. A gente chama a terra de mãe porque é dela que a gente sobrevive, dela que a gente nasce, nasce fruto. E as crianças de hoje são uma semente. Seu Alcindo sempre fala que a gente dá semente, depois a gente vai embora, vai para o céu, e nossos filhos carregam esse conhecimento adiante. O conhecimento que a gente tem é muito amplo, e quem está caminhando por esse caminho da espiritualidade tem que conhecer todos os detalhes. A gente vai aprender muito mais do que na universidade, principalmente a universidade de vocês. A universidade da espiritualidade é muito ampla, não acaba, a gente vai aprendendo mais, a gente vai caminhando, vai crescendo, vai ficando velhinho e vai aprendendo mais. É infinito. Mesmo assim, a gente vai dando conselho, dando ensinamento para as crianças, os jovens, que podem caminhar também, com pé no chão, firme. Caminhando com força, fortalecimento que busca essa esperança no futuro, que possa repassar para as futuras gerações. Eu estou repassando um pouquinho do que eu aprendi com o seu Alcindo. Esse é o nosso conhecimento, repassado de geração em geração.

Espero que a gente vá se unir, vá entrelaçar esse conhecimento, o conhecimento de vocês e o nosso conhecimento. Que possamos caminhar todos juntos por esse caminho, porque o caminho da nossa vida de hoje é muito difícil. A gente tem muitos obstáculos pela frente, então às vezes a gente tropeça. Como o seu Alcindo falou ontem no encontro: antes da gente sair para o trabalho, para o estudo, a gente não para para sentar um pouquinho e pedir para o Grande Espirito, que possa caminhar bem. Ir lá e voltar para casa. Porque às vezes a nossa vida, a nossa caminhada, a nossa ida é muito longa, a gente pode ir e não voltar.

\footnotetext{
${ }^{21}$ O termo aguydjevete está relacionado ao conceito de aguydje, que significa aproximadamente "perfeição", "completude", ou ainda "imortalidade do espírito"; "superação da condição humana" (MELLO, 2006, p. 35), enquanto o sufixo ete quer dizer "verdadeiro". Assim, uma tradução aproximada para aguydjevete seria "perfeição verdadeira". A expressão remete ao tema da instabilidade e provisoriedade da condição humana: para os mbya, a humanidade oscila entre dois polos: a perfeição ou divinação em vida - aguydje - a que aspira e a transformação animal possível, ameaça sempre presente (PISSOLATO, 2007).

22 Expressão Lakota muito usada pelos membros do Fogo Sagrado, comumente traduzida como "por todas as nossas relações". Durante sua pesquisa de campo, várias vezes, Isabel de Rose notou pessoas que transitam na rede da Aliança das Medicinas usando os termos aguydjevete e aho mitakuye oyas'in de forma intercambiável (ROSE, 2010).
} 
Então a gente tem que parar e pensar, e pedir para o Grande Espírito que possa abrir o nosso caminho. Que o nosso trabalho seja mais tranquilo, nosso estudo seja mais tranquilo, e a gente volte para casa com tranquilidade. Porque às vezes falta isso para nós. Às vezes a gente tem tanta coisa na mente, tanta coisa para fazer, a gente esquece de nós [mesmos]. Eu sei por mim mesmo. Às vezes o seu Alcindo pega na minha orelha [e diz]: "você não para e pensa?". Porque às vezes a gente quer fazer tudo de uma vez só, e acaba não fazendo tudo. Acaba esquecendo alguma coisa, deixa para depois, e vai acumulando as coisas. É isso que os mais velhos repassam para nós: que a nossa vida é uma só, e nós temos que cuidar da nossa vida. Ter boas relações com todos no universo. Então acho que [esse] é um conhecimento que podemos repassar para cada um de vocês, como é que é a vida, o cotidiano, na aldeia, principalmente. Porque na comunidade indígena tem um tempo diferente, tem que fazer uma coisa de cada vez. Bastante coisa de uma vez só não vai dar certo. E no mundo de vocês já é diferente, horário, é tudo marcadinho. Às vezes vocês ficam até perdidos, não sei se eu vou para cá ou vou para lá, fazer as coisas aqui ou não. Às vezes acaba não fazendo nada, esquece tudo. Então no nosso costume dentro da comunidade o tempo é regular, tempo devagar. Com cada passinho a gente vai fazendo a construção, construir o pilar da nossa vida. Esse é um conhecimento que a gente tem, que podemos repassar para as novas gerações que estão vindo. Mas alguns índios que estão na aldeia também, principalmente as lideranças, o cacique, eles têm que ter dois conhecimentos, do mundo não-indígena e do mundo indígena. Porque já vão partir para a política, que não é da cultura. Então, a liderança tem que estar bem formada. E liderança espiritual já é diferente, é da comunidade, da natureza, pode fortalecer as crianças, a cultura, o costume, para não se perder. Porque hoje o mundo está um pouco maluco, né. A gente mesmo fica perdido. Mas quem é o pilar da comunidade? São os mais velhos. Por isso a gente fortalece mais os anciões, os mais velhos da comunidade, porque a gente diz que é o conhecimento deles que está mantendo essa cultura. A gente fala que eles são uma biblioteca viva, têm todas as histórias. Os nossos costumes na comunidade são dessa maneira, ligados à natureza [...].

Nós [estamos] aqui, para repassar um pouco de sabedoria... Como a cultura indígena se relaciona com o universo e a natureza... Não sei se vocês estão me entendendo. Às vezes o meu português é muito complicado... Mas espero que sintam no coração de cada um, que possamos ter união, ter a força, ter o conhecimento para a nossa caminhada, e repassar um pouco dessa experiência para as novas gerações que estão vindo [...].

(Geraldo Karaí Okenda, aulas ministradas na UFMG em maio de 2015)

\section{Reflexões Finais}

Neste texto abordamos o material das aulas ministradas por Alcindo Wherá Tupã e Geraldo Karaí Okenda na disciplina "Curas e cuidados", que aconteceu na UFMG em 2015, como parte da Formação Transversal em Saberes Tradicionais. Buscamos estabelecer relações tanto com uma reflexão sobre o Encontro de Saberes e sua potencialidade, quanto com o material das nossas pesquisas anteriores realizadas na aldeia Yynn Morothi Wherá.

Aspectos que chamaram nossa atenção nas aulas incluem a criatividade presente nas narrativas de seu Alcindo, e especialmente de Geraldo, ao levantar pontos centrais da cosmologia e do sistema xamânico guarani e ao mesmo tempo procurar traduzi-los para o público não-indígena que participou da disciplina. Como indicamos anteriormente, isto possivelmente aponta para uma atualização do papel do xamã no mundo contemporâneo. Assim, além de ser responsável por viajar entre os diferentes mundos que compõem 
o cosmos e negociar entre os distintos seres (humanos e não humanos) que habitam esses mundos, os xamãs indígenas de hoje também são responsáveis pelas negociações cosmopolíticas e pelas conexões com o "mundo não-indígena". Essas negociações frequentemente passam pela tradução de conceitos que fazem parte do pensamento e da cosmovisão indígena. Essas traduções muitas vezes são feitas buscando analogias com aspectos da vida atual - por exemplo, a comparação do petynguá com o celular. Entretanto, como indicamos, é preciso lembrar que sempre há limites e equívocos envolvidos nesses processos de tradução.

Como vimos, o trânsito de grupos e representantes indígenas nos circuitos da Nova Era e da ayahuasca no Brasil e as alianças entre grupos indígenas e grupos espirituais não indígenas vêm se multiplicando ao longo dos últimos vinte anos. Nesse sentido, cabe destacar que as falas de seu Alcindo e Geraldo nas aulas ministradas na UFMG apontam para agenciamentos criativos de imagens associadas a um xamanismo indígena genérico de ampla circulação nessas redes, e também em outros contextos, tais como as do "indígena espiritual" e "ecológico", do "resgate do passado" e da "medicina tradicional". Tanto as traduções dos conceitos indígenas quanto os agenciamentos dessas imagens são realizados de modo a chamar atenção para os direitos, demandas e reivindicações políticas dos povos indígenas, em termos gerais e também em contextos particulares, ligados a famílias e a comunidades específicas.

\section{Agradecimentos}

Gostaríamos de agradecer a todos os mestres e mestras com quem tivemos a oportunidade de conviver e de aprender durante nossa colaboração com a Formação Transversal em Saberes Tradicionais da UFMG, entre 2014 e 2017. Agradecemos também a todos os(as) colegas que fazem parte da equipe desse programa. Este trabalho contou com o apoio do CNPq e da CAPES, via bolsa PDJ e PNPD, respectivamente. Contou ainda com recursos da Formação Transversal em Saberes Tradicionais e da PROGRAD/UFMG. Dedicamos este texto à memória da tchedjaryi Rosa Poty Djá.

\section{Referências}

ALBERT, Bruce. O ouro canibal e a queda do céu. Uma crítica xamânica da economia política da natureza (Yanomami). In: ALBERT, Bruce; RAMOS, Alcida (org.) Pacificando o branco: Cosmologias do contato no Norte-Amazônico. São Paulo: Editora da UNESP, 2002. p. 239-275.

ASSIS, Valéria de; GARLET, Ivori J. Análise sobre as populações guarani contemporâneas: demografia, espacialidade e questões fundiárias. Revista de Índias, [s.l.], v. LXIV, n. 230, p. 35-54, 2004.

BARBOSA NETO, Edgar R.; ROSE, Isabel S.; GOLDMAN, Marcio (org.). Encontro de saberes: transversalidades e experiências (dossiê). Revista Mundaú, [s.l.], v. 9, n. 1, p. 306, 2020.

BARTOLOMÉ, Miguel A. Oguerojera (desplegarse). La etnogénesis del pueblo mbya-guaraní. Ilha, [s.l.], v. 10, n. 1, p. 105-140, 2008.

BRASIL, André G. et al. Proposta do Programa de Formação Transversal em Saberes Tradicionais, enviada à PROGRAD da UFMG. [S.l.: s.n.], 2014. 
CANDAU, Vera Maria F. Educacion intercultural en America Latina: distintas concepciones y tensiones actuales. Estudos Pedagógicos, [s.l.], v. 36, n. 2, p. 333-342, 2010.

CANDAU, Vera Maria F.; RUSSO, Kelly. Interculturalidade e educação na América Latina: uma construção plural, original e complexa. Revista Diálogo Educacional, [s.l.], v. 10, n. 29, p. 151-169, 2010.

CARNEIRO DA CUNHA, Manuela. Xamanismo e tradução. In: CARNEIRO DA CUNHA, Manuela Cultura com aspas. São Paulo: CosacNaify, 2009. p. $101-114$.

CARVALHO, José Jorge. Los estúdios culturales en America Latina: interculturalidade, acciones afirmativas y encuentro de saberes. Tabula Rasa, [s.l.], v. 12, p. 229-251, 2010.

CARVALHO, José Jorge. Inclusão étnica e racial no Brasil: a questão das cotas no ensino superior. São Paulo: Attar Editorial, 2011.

CARVALHO, José Jorge; VIANNA, Letícia C. Rodrigues. O Encontro de Saberes nas universidades. Uma síntese dos dez primeiros anos. Revista Mundaú, [s.l.], v. 9, n. 1, p. 23-49, 2020.

CHAUMEIL, Jean-Pierre. Ver, saber, poder: El chamanismo de los Yagua de la Amazônia Peruana. Peru: IFEA, CAAP, CAEA/CONICET, 1998.

CHAUMEIL, Jean-Pierre. Varieties of Amazonian shamanism. Diógenes, [s.l.], v. 158, p. 101-113, 1992.

CICCARONE, Celeste. Drama e sensibilidade. Migração, xamanismo e mulheres mbya guarani. 2001. 415p. Tese (Doutorado em Antropologia Social) - Pontifícia Universidade Católica, São Paulo, 2001.

CICCARONE, Celeste. Drama e sensibilidade: migração, xamanismo e mulheres mbya. Revista de Índias, [s.l.], v. LXIV, n. 230, p. 81-96, 2004.

DARELLA, Maria Dorothea. Territorialidade e territorialização guarani no litoral de Santa Catarina. Tellus, [s.l.], v. 4, n. 6.1, p. 79-110, 2004.

GOW, Peter. River people: shamanism and history in Western Amazônia. In: THOMAS, Nicolas; HUMPHREY, Caroline (org.) Shamanism, history and the State. Ann Arbor: University of Michigan Press, 1994. p. 90-114.

GUIMARÃES, César et al. Por uma universidade pluriepistêmica: a inclusão de disciplinas ministradas por mestres dos saberes tradicionais e populares na UFMG. Tessituras, [s.l.], v. 4, n. 2, p. 179-201, 2017.

KOPENAWA, Davi Y.; ALBERT, Bruce. A queda do céu: palavras de um xamã yanomami. São Paulo: Companhia das Letras, 2010.

LABATE, Beatriz C.; ARAÚJO, Wladimyr S. (org.) O uso ritual da ayahuasca. 2. ed. Campinas: Mercado de Letras; FAPESP, [2002] 2004.

LABATE, Beatriz C.; CAVNAR Clancy Cavnar (org.) Ayahuasca shamanism in the Amazon and beyond. New York: Oxford University Press, 2014.

LABATE, Beatriz C.; COUTINHO, Thiago. O meu avô deu ayahuasca a para o Mestre Irineu: reflexões sobre a entrada dos índios no circuito urbano de consumo de ayahuasca no Brasil. Revista de Antropologia, [s.l.], v. 57, n. 2, p. 216-250, 2014.

LADEIRA, Maria Inês. O caminhar sob a luz: Território mbya à beira do oceano. São Paulo: Editora da UNESP, 2007.

LANGDON, Esther Jean (org.). Xamanismo no Brasil: novas perspectivas. Florianópolis: Editora da UFSC, 1996.

LANGDON, Esther Jean. Redes xamânicas, curandeirismo e processos interétnicos: uma análise comparativa. Mediações, [s.l.], v. 17, n. 1, p. 61-84, 2012. 
LANGDON, Esther Jean. La negociación de lo oculto: chamanismo, medicina y familia entre los Siona del bajo Putumayo. Popayán: Editorial Universidad del Cauca, 2015.

LANGDON, E. Jean; ROSE, Isabel S. Contemporary Guarani shamanisms: "traditional medicine" and discourses of native identity in Brazil. Health, Culture and Society, [s.l.], v. 3, n. 1, p. 29-48, 2012.

LANGDON, E. Jean; ROSE, Isabel S. Medicine Alliance: contemporary shamanic networks in Brazil. In: LABATE, Beatriz Caiuby; CAVNAR, Clancy (org.). Ayahuasca shamanism in the Amazon and beyond. New York: Oxford University Press, 2014. p. 81-104.

LOSONCZY, Anne-Marie; MESTURINI, Silvia. La selva viajera. Rutas del chamanismo ayahuasquero entre Europa y América. Religião e Sociedade, [s.l.], v. 30, n. 2, p. 164-183, 2010.

MACEDO, Valéria. Nexos da diferença: cultura e afecção em uma aldeia guarani na Serra do Mar. 2010. 331p. Tese (Doutorado em Antropologia Social) - Universidade de São Paulo, São Paulo, 2010.

MACEDO, Valéria. Tracking Guarani songs: between villages, cities and worlds. Vibrant, [s.l.], v. 8, n. 1, p. 377-411, 2011.

MELLO, Flávia Cristina. Aetchá nhanderukuery karai retarã: entre deuses e animais. Xamanismo, parentesco e transformação entre os Chiripá e Mbyá Guarani. 2006. 300p. Tese (Doutorado em Antropologia Social) - Universidade Federal de Santa Catarina, Florianópolis, 2006.

MONTARDO, Deisy L. Oliveira. Através do mbaraka: música dança e xamanismo Guarani. São Paulo: EdUSP, 2009.

MONTARDO, Deisy L. Oliveira; RUFINO, Márcia Regina C. F. (org.). Saberes e ciência plural: diálogos e interculturalidade em antropologia. Florianópolis: Editora da UFSC; Instituto Brasil Plural, 2017.

OLIVEIRA, Diogo. Arandu nhembo'ea: cosmologia, agricultura e xamanismo entre os Guarani-Chiripá no litoral de Santa Catarina. 2011. 283p. Dissertação (Mestrado em Antropologia Social) - Universidade Federal de Santa Catarina, Florianópolis, 2011.

PIMENTEL, S. et al. Relatório circunstanciado de identificação e delimitação da Terra Indígena Tenondé Porã. Brasília, DF: CGID; FUNAI, 2010.

PISSOLATO, Elizabeth. A duração da pessoa: mobilidade, parentesco e xamanismo mbya (Guarani). São Paulo: Editora da UNESP, 2007.

ROSE, Isabel S. Tata endy rekoe - Fogo Sagrado: encontros entre os Guarani, a ayahuasca e o Caminho Vermelho. 2010. 435p. Tese (Doutorado em Antropologia Social) - Universidade Federal de Santa Catarina, Florianópolis, 2010.

ROSE, Isabel S. Notas sobre os usos contemporâneos do peiote e o Fogo Sagrado de Itzachilatlan. In: LABATE, Beatriz C.; GOULART, Sandra Lucia (org.). O uso de plantas psicoativas nas Américas. Rio de Janeiro: Gramma; NEIP, 2019. p. 347-364.

ROSE, Isabel S.; LANGDON, Esther J. Chamanismos guarani contemporâneos en Brasil: un estudio de transfiguración cultural. Revista Colombiana de Antropologia, [s.l.], v. 49, n. I, p. 105-127, 2013.

SCHADEN, Egon. Aspectos fundamentais da cultura Guarani. São Paulo: EdUSP, [1954] 1974.

STOLZE LIMA, Tânia. A planta redescoberta: um relato do encontro da ayahuasca com o povo Yudjá. Revista do Instituto de Estudos Brasileiros, [s.l.], v. 69, p. 118-136, 2018.

VIVEIROS DE CASTRO, Eduardo. Perspectival anthropology and the method of controlled equivocation. Tipiti, [s.l.], v. 2, n. 1, p. 3-22, 2004. 
WALSH, Catherine. Estudos (inter)culturais na chave descolonial. Tabula Rasa, [s.l.], v. 12, n. 1, p. 209-227, 2010.

WHERÁ TUPÃ, Alcindo Moreira; OKENDA, Geraldo Karaí. Aulas ministradas na disciplina "Artes e ofícios dos saberes tradicionais: curas e cuidados": na Formação Transversal em Saberes Tradicionais da UFMG. [S.l.: s.n.], 2015.

\section{Isabel Santana de Rose}

Doutora em Antropologia Social pela UFSC. Professora Visitante no Programa de Pós-Graduação em Antropologia da Universidade Federal de Alagoas (PPGAS/UFAL).

Endereço profissional: Av. Lourival Melo Mota, s/n, Tabuleiro do Martins, Maceió, AL. CEP: 57072-900.

E-mail: belderose@gmail.com

ORCID: https://orcid.org/0000-0001-5629-8203

\section{Geraldo Karaí Okenda}

Professor e Pesquisador guarani. Graduado no curso de Licenciatura Intercultural Indígena do Sul da Mata Atlântica pela UFSC. Professor na Formação Transversal em Saberes Tradicionais da UFMG.

Endereço profissional: Aldeia Yynn Morothi Wherá, BR 101, Praia João Rosa, Biguaçu, SC. CEP: 88160-000. E-mail: karaigeraldo@gmail.com

\section{Como referenciar este artigo:}

ROSE, Isabel Santana de; OKENDA, Geraldo Karaí. Xamanismos Guarani e Tradução no Encontro de Saberes. Ilha - Revista de Antropologia, Florianópolis, v. 23, n. 3, p. 21 -40, setembro de 2021. 